\title{
Identifikasi tingkat perkembangan remaja siswa SMA di kota Singkawang pada aspek landasan hidup religius
}

\author{
Iip Istirahayu ${ }^{1 *}$, Dian Mayasari² \\ ${ }^{12}$ STKIP Singkawang, Singkawang Indonesia. \\ Korespondensi: $\bowtie$ iip_istirahayu@yahoo.com
}

\begin{abstract}
Every Man has always been progressing in a phase of life. Disturbance at one stage will hinder the development as a whole. The purpose this research is to identify the level of development of adolescents of high school students in Singkawang on a foundation of religious life aspect. This research is a quantitative inferential. The study was conducted on the 12 SMA in Singkawang. Data collection technique is using the Inventory Task Progress (ITP). Data were analyzed using Task Analysis Progress (ATP) with the adoption of the categories in the Encoding level of development. The results showed that the development of adolescent high school students in Singkawang on the runway area religious life is one school located at saksama level and $11^{\text {th }}$ schools at the level of individuality.
\end{abstract}

Keywords: The Task of Development, Adolescents, Religious

Cara Mengutip Artikel: Istirahayu, i., \& Mayasari, D. (2017). Identifikasi tingkat perkembangan remaja siswa SMA di kota Singkawang pada aspek landasan hidup religius. In Ifdil, I., Bolo Rangka,I., \& Adiputra, S. (Eds.), Seminar \& Workshop Nasional Bimbingan dan Konseling: Jambore Konseling 3 (pp. 93-97). Pontianak: Ikatan Konselor Indonesia (IKI)

(c) 2017. This is an open access article distributed under the Creative Commons Attribution License, which permits unrestricted use, distribution, and reproduction in any medium, provided the original work is properly cited.

\section{Pendahuluan}

Siswa Sekolah Menengah Atas (SMA) dikatakan remaja. Siswa SMA sebagai individu yang berada pada tugas perkembangan usia remaja, seyogyanya mampu menerima dan menyesuaikan diri, bersikap positif terhadap pernikahan dan hidup berkeluarga, dan mengamalkan ajaran agama.

Masa remaja adalah masa transisi dalam rentang kehidupan manusia, menghubungkan masa kanak-kanak dan masa dewasa (Santrock, 2003).

Havighurst (1961) menjelaskan tugas perkembangan yang seharusnya dicapai pada periode remaja. Satu diantaranya yaitu mengamalkan ajaran agama. Perkembangan yang terkait dengan mengamalkan ajaran agama termasuk di dalam wilayah landasan religius. 
Tugas perkembangan itu merupakan suatu tugas yang muncul pada periode tertentu dalam rentang kehidupan individu, yang apabila tugas itu dapat berhasil dituntaskan akan membawa kebahagiaan dan kesuksesan dalam menuntaskan tugas-tugas berikutnya; sementara apabila gagal, maka akan menyebabkan ketidakbahagiaan pada diri individu yang bersangkutan, menimbulkan penolakan masyarakat, dan kesulitan-kesulitan dalam menuntaskan tugas-tugas berikutnya (Havighrust, 1961).

Tidak tuntasnya tugas perkembangan pada individu menyebabkan ketidakbahagiaan dan penolakan dari masyarakat. Beberapa kasus yang terjadi akibat dari tidak tuntasnya tugas perkambangan pada siswa diantaranya stress, kejenuhan, tidak percaya diri, agresivitas yang menyebabkan semakin tingginya angka tawuran antar pelajar, pergaulan bebas, aborsi, dan tindak kejahatan lainnya.

Berdasarkan latar belakang permasalahan yang ada, perlu adanya identifikasi tingkat perkembangan remaja yang tujuannya adalah untuk merancang program yang terkait dengan layanan bimbingan dan konseling bagi remaja agar mampu melalui tugas perkembangannya dengan baik.

\section{Metode}

Jenis penelitian ini adalah kuantitatif inferensial. Tempat penelitian SMA di kota Singkawang. Populasi penelitian adalah SMA Negeri dan Swasta. Sampel penelitian ini remaja SMA kelas $X$ dari 10 sekolah SMA yang ada di kota singkawang. Teknik pengumpulan data yang digunakan dalam penelitian ini adalah dengan melakukan pemeriksaan jawaban siswa atas pernyataan yang diajukan pada Inventori Tugas Perkembangan (ITP).

Data yang diperoleh dari hasil sebaran inventori tugas perkembangan selanjutnya di olah menggunakan aplikasi Analisis Tugas Perkembangan dan tingkat berdasarkan tingkat perkembangan (Kartadinata, S., dkk).

Skor dan Kode Tingkat Tingkat SLTA

Skor $3=$ KOM (KONFORMITAS)

Skor $4=$ SDI (SADAR DIRI)

Skor 5 = SAK (SAKSAMA)

Skor 6 = IND (INDIVIDU)

\section{Hasil dan Pembahasan}

Pada aspek landasan religius, tingkat perkembangan remaja siswa SMA dari 12 sekolah yang diteliti menunjukkan hasil seperti pada grafik di bawah ini. 


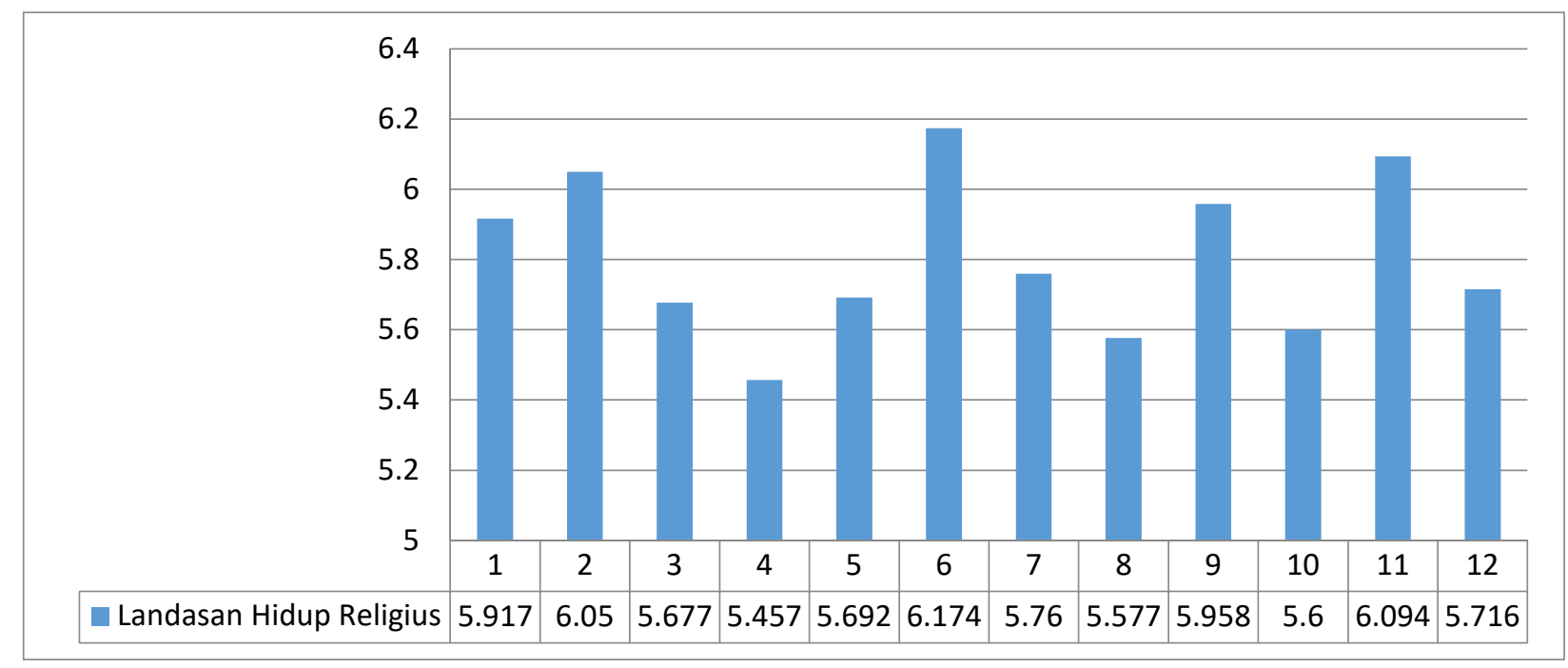

Grafik 1. Landasan Hidup Religius

Grafik 1 menunjukkan tingkat perkembangan remaja SMA dari 12 sekolah yang diteliliti pada aspek landasan hidup religius. Tingkat perkembangan remaja SMA di kota singkawang pada aspek landasan hidup religius berada pada antara skor 5 dan 6 yang artinya, tingkat perkembangan berada pada tingkat tahap SAK (Saksama) dan IND (Individualitas).

Lebih rinci, hasil penelitian setiap sekolah dan rata-rata skor dari 12 sekolah terlihat pada Tabel 1.

Tabel 1. Tingkat Perkembangan pada Aspek Landasan Hidup Religius

\begin{tabular}{llll}
\hline No Nama Sekolah Skor & Kode & Keterangan
\end{tabular}

Tingkat Perkembangan

KOM SDI SAK IND

$3 \quad 4 \quad 5 \quad 6$

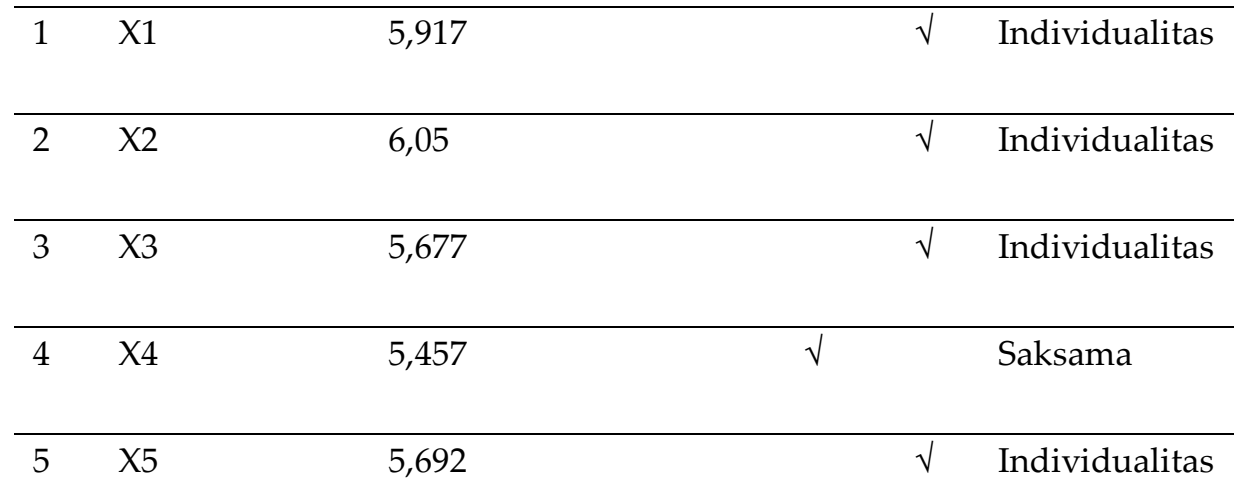




\begin{tabular}{|c|c|c|c|c|c|c|c|}
\hline \multirow[t]{4}{*}{ No } & \multirow[t]{4}{*}{ Nama Sekolah } & \multirow[t]{4}{*}{ Skor } & \multicolumn{4}{|c|}{ Kode } & \multirow[t]{4}{*}{ Keterangan } \\
\hline & & & \multicolumn{4}{|c|}{ Tingkat Perkembangan } & \\
\hline & & & KOM & SDI & SAK & IND & \\
\hline & & & 3 & 4 & 5 & 6 & \\
\hline 6 & $\mathrm{X} 6$ & 6,174 & & & & $\sqrt{ }$ & Individualitas \\
\hline 7 & $\mathrm{X} 7$ & 5,76 & & & & $\sqrt{ }$ & Individualitas \\
\hline 8 & $\mathrm{X} 8$ & 5,577 & & & & $\sqrt{ }$ & Individualitas \\
\hline 9 & X9 & 5,958 & & & & $\sqrt{ }$ & Individualitas \\
\hline 10 & $\mathrm{X} 10$ & 5,6 & & & & $\sqrt{ }$ & Individualitas \\
\hline 11 & $\mathrm{X} 11$ & 6,094 & & & & $\sqrt{ }$ & Individualitas \\
\hline 12 & $\mathrm{X} 12$ & 5,716 & & & & $\sqrt{ }$ & Individualitas \\
\hline Rata & -rata & $5.806=$ & Tahap & NDIV & [DUA] & ITAS & \\
\hline
\end{tabular}

Tabel 1 menunjukkan bahwa terdapat satu sekolah berada pada tingkat tahap SAKSAMA. Artinya, rata-rata remaja SMA di sekolah X4 bertindak atas dasar nilai internal dan mampu meliahat diri sebagai pembuat pilihan dan pelaku tindakan.

Sekolah dengan tingkat tahap INDIVIDUAL terdapat pada sebelas (11) sekolah. Artinya, remaja SMA di sebelas sekolah tersebut mampu meningkatkan kesadaran diri, menyadari konflik emosional antara kemandirian dan ketergantungan.

Hasil penelitian berdasarkan pemetaan secara kelompok, untuk perindividu dapat melakukan analisis data perindividu dari sekolah masing-masing. Data perindividu pada aspek landasan religius dapat digunakan sebagai need assemen dalam menentukan program bimbingan dan konseling di sekolah.

\section{Kesimpulan}

Tingkat perkembangan remaja siswa SMA di Kota Singkawang pada aspek landasan hidup religious terdapat 1 sekolah pada tingkat SAKSAMA dan 11 sekolah pada tingkat INDIVIDUAL. 


\section{Ucapan Terima Kasih}

Ucapan terima kasih disampaikan kepada pihak-pihak yang membantu dalam penelitian hingga publish jurnal.

1. Andi Mursidi, M.Si., selaku Ketua STKIP Singkawang yang memberikan motivasi berupa dana penelitian dan peluang bagi dosen dalam melaksanakan tugas tridarma perguruan tinggi dan mengembangkan kualitas diri sebagai dosen.

2. Sekolah-sekolah SMA Negeri dan Swasta di kota Singkawang yang menjadi sampel penelitian.

3. Mahasiswa STKIP Singkawang yang terlibat dalam penelitian ini.

\section{Daftar Rujukan}

Havighurst. (1961). Human Develoment \& Education. New York: David Mckay Co.

Santrock. J. W. (2003). Adolescence: Perkembangan Remaja.(edisi keenam) Jakarta: Erlangga.

Sunaryo, Kaaartadinata., dkk. (2007). Inventori Tugas Perkembangan Manual Guide ATP Versi 3.5. Bandung: Universitas Pendidikan Indonesia.

Yusuf, S., \&, Nurihsan, A. Juntika. (2007). Penyusunan Program Bimbingan dan Konseling Berbasis Perkembangan. Bandung: Universitas Pendidikan Indonesia. 